\title{
Modelling the volcanic ash plume from Eyjafjallajökull eruption (May 2010) over Europe: evaluation of the benefit of source term improvements and of the assimilation of aerosol measurements
}

\author{
Matthieu Plu ${ }^{1}$, Guillaume Bigeard ${ }^{1}$, Bojan Sič $^{1}$, Emanuele Emili $^{2}$, Luca Bugliaro ${ }^{3}$, Laaziz El Amraoui ${ }^{1}$, \\ Jonathan Guth ${ }^{1}$, Beatrice Josse ${ }^{1}$, Lucia Mona ${ }^{4}$, and Dennis Piontek ${ }^{3}$ \\ ${ }^{1}$ CNRM, Université de Toulouse, Météo-France, CNRS, Toulouse, France \\ ${ }^{2}$ CECI, Université de Toulouse, Cerfacs, CNRS, Toulouse, France \\ ${ }^{3}$ Deutsches Zentrum für Luft- und Raumfahrt e.V. (DLR), Oberpfaffenhofen, Germany \\ ${ }^{4}$ CNR-IMAA, Consiglio Nazionale delle Ricerche, Istituto di Metodologie per l'Analis Ambientale, Tito (PZ), Italy \\ Correspondence: Matthieu Plu (matthieu.plu@meteo.fr)
}

\begin{abstract}
.
Numerical dispersion models are used operationally worldwide to mitigate the effect of volcanic ash on aviation. In order to improve the representation of the horizontal dispersion of ash plumes and of the 3D concentration of ash, a study was conducted using the MOCAGE model during the EUNADICS-AV project. Source term modelling and assimilation of different data were investigated. A sensitivity study to source term formulation showed that a resolved source term, using the FPLUME plume-rise model in MOCAGE, instead of a parameterised source term, induces a more realistic representation of the horizontal dispersion of the ash plume. The FPLUME simulation provides more concentrated and focused ash concentrations in the horizontal and the vertical dimensions than the other source term. The assimilation of MODIS Aerosol Optical Depth has an impact on the horizontal dispersion the plume, but this effect is rather low and local, compared to source term improvement. More promising results are obtained with the continuous assimilation of ground-based lidar profiles, which improves the vertical distribution of ash and helps to reach realistic values of ash concentrations. The improvement can remain several hours after and several hundred kilometers away downstream to the assimilated profiles.
\end{abstract}

\section{Introduction}

Volcanic ash is a potential threat to aircraft engines (Clarkson et al., 2016), and the atmospheric transport of ash clouds can cause severe perturbations and even disruptions to air traffic, and large economic losses (IATA, 2010). Continuous monitoring of ash clouds worldwide has been the duty of Volcanic Ash Advisory Centres (VAAC), that issue warnings and information in their respective domain of responsibility (ICAO, 2016). They provide at least qualitative information (ie, presence of ash in different vertical layers, at different forecast lead times), but also more quantitative estimates. In Europe, the London and Toulouse VAAC issue messages when volcanoes erupt in their domain of duty, to warn of the presence of ash in different vertical layers. Since the Eyjafjallajoküll eruption in 2010, they have also provided concentration charts at different vertical levels (ICAO, 2016) for different thresholds: $<2 \mathrm{mg} \cdot \mathrm{m}^{-3}$ (low contamination), $>2 \mathrm{mg} \cdot \mathrm{m}^{-3}$ and $<4$ mg.m ${ }^{-3}$ (medium contamination), 
and $>4 \mathrm{mg} \mathrm{m}^{-3}$ (high contamination). Such forecast charts (up to 18 hours ahead) indicate different levels of hazardous zones and they should be used by authorities for flight safety. The general purpose of these thresholds is to apply refined decisions of flying according to the tolerance of aircraft engines to ash concentrations.

In order to issue reliable forecasts, outputs from numerical dispersion models are widely used, combined with observations from satellites or ground-based stations. However, accurate forecasts of ash concentrations in near-real time remains a challenge, due to the availability of data and to the uncertainties and remaining deficiencies in models. As a consequence, active research is on-going to improve their performance (Beckett et al., 2020), while remaining cost-effective to deliver data and warnings in a timely operational context. Some limitations in models come from the resolution (horizontal, vertical, time step), from the representation of turbulence and diffusion, but also from the representation of aerosol microphysical processes (aggregation, sedimentation), and specifically of volcanic ash.

The volcanic source terms, i.e. the mass (per size of particles) of ash that is injected in the atmosphere as a function of height and time, is prone to large uncertainties and is another domain of active research. Different levels of complexity of source terms have been developed and can be used, which consist in deriving eruptions parameters (mass eruption rate - MER -, vertical profiles of injection of ash mass, grain size distribution, etc), from sparse and uncertain input measured data (plume height, ash columns, etc). "Parameterised" source terms (such as Mastin et al., 2009) provide values or analytical relationships between the eruption parameters based on past eruptions data; with the advantage of requiring very low computational resources. "Resolved" source terms are the result of an explicit simulation of the thermodynamic and buoyancy processes in the plume (such as the steady 1-D model PLUMERIA, Mastin, 2007), and even the microphysical aerosol processes, including aggregation (FPLUME, Folch et al., 2016). Source inversion of volcanic ash columns measured by satellites has also been developed in different institutes (Stohl et al., 2011; Steensen et al., 2017a; Beckett et al., 2020), to generate source terms that improves the match of model columns with observed columns, but in delayed time of several hours due to the availability of observations and of time to run the inversion scheme. Inversion requires an a priori that must be based on a parameterised or a resolved source term, and some studies have shown that the uncertainty of the result of inversion is more linked to the uncertainty of the a priori than to the uncertainty of observations (Steensen et al., 2017b). Improving the physical representation of source terms is thus a critical topic.

One of the purpose of the EUNADICS-AV project (Hirtl et al., 2019) was to develop and assess the integration of observations for air flight applications. Measurements from satellites, from ground-based stations were considered for assimilation in dispersion models, which deserves particularly to be investigated when the ash cloud gets far from the volcano source. In particular, the proven benefits of assimilation of aerosol optical depth (AOD, Sič et al., 2016) and of lidar data (El Amraoui et al., 2020) for the 3D representation of aerosols should also be assessed for volcanic ash.

The present article assesses the relative performance of different source term and of the assimilation of satellite and groundbased data for the representation of 3-D concentrations of ash during a phase of the eruption of Eyjafjallajoküll in 2010. The experiments are done with the MOCAGE model, which is the model developed and used by Toulouse VAAC, and which has a capacity for data assimilation. 
The plan of the article is as follows. Section 2 presents the MOCAGE model and the different observation datasets that are used on the case study. In Section 3, the different source terms are presented and their performance are compared. Section 4, the assimilation of ground-based lidar data is presented and assessed compared to in-situ measurements of ash concentrations. The conclusion in Section 5 includes a short discussion about the perspectives of the study.

\section{Case study}

\subsection{Eyjafjallajökull eruption episode (13-20 May 2010)}

The study focuses on a particular period of the eruption of Eyjafjallajökull in 2010, when ashes spread across the North Sea and the Atlantic Ocean, and fly over continental Europe. During this period, lidar observations from EARLINET (Pappalardo et al., 2013) and airborne measurements (Schumann et al., 2011) of aerosols were acquired, that detected layers of significant ash concentrations. These data can be used for assimilation and for evaluation (Fig. 1). During this period, ash data retrieved from SEVIRI algorithm (Bugliaro et al., 2021; Piontek et al., 2021b) are also available and can be used for evaluation of the horizontal dispersion of ash.

\subsection{MOCAGE configuration}

MOCAGE is a chemistry-transport model that is used for operational and research applications at Meteo-France. The MOCAGE configuration used in the present study complies with the one described by Guth et al. (2016): it has full tropospheric and stratospheric chemistry, primary aerosols (desert dust, sea salts, volcanic ash, black carbon and organic carbon) and secondary aerosols (sulfate, nitrate, ammonium). The aerosols undergo various processes, as described by Guth et al. (2016): transport (advection and sub-grid transport), sedimentation, deposition (dry and wet) and interaction with gas-phase chemistry. The aerosol bins are the same for all types of aerosols, except for ash, ranging from $2 \mathrm{~nm}$ to $50 \mu \mathrm{m}$ with size bin limits of 2 , 10 , and $100 \mathrm{~nm}$, and 1, 2.5, 10 and $50 \mu \mathrm{m}$. For volcanic ash, the model bins are defined on the $\phi$-scale classes (Krumbein, 1934), such as bin 1 corresponds to the $\phi$-bins 10 and 9 , bin 2 is $\phi$-bin 8 , bin 3 is $\phi$-bin 7 , bin 4 is $\phi$-bin 6 , bin 5 is $\phi$-bin 5 and bin 6 is $\phi$-bin 4 . This covers the size spectrum of fine ash (between diameter $2^{-4} \mathrm{~mm}=62.5 \mu \mathrm{m}$ ) and diameter $2^{-10} \mathrm{~mm} \simeq 1 \mu \mathrm{m}$ ), that can be transported on a long distance.

The MOCAGE simulations run on a global domain at $1^{\circ}$ resolution, and on a large European domain at $0.2^{\circ}$ resolution, called MACC02. The lateral boundary conditions for the smaller domain are provided by the global domain. The diagnostics are done on a subset of the European simulation domain (Fig. 1). Input meteorological forcings are provided with a 3-hours frequency: they come from ARPEGE 6-hourly analyses, interspersed with 3-hours forecasts. MOCAGE has 47 vertical hybrid sigma-pressure levels from the surface up to $5 \mathrm{hPa}$. The vertical resolution varies with altitude, with a resolution of $40 \mathrm{~m}$ in the planetary boundary layer, about $400 \mathrm{~m}$ in the free troposphere and about 700-800 $\mathrm{m}$ in the upper troposphere and lower stratosphere. 
The assimilation scheme in MOCAGE (Massart et al., 2009) relies on variational methods, it can be 3D-VAR or 3D-FGAT (Sič et al., 2016). Assimilation of observations is done on the MACC02 domain. For the assimilation of aerosol observations, the control vector is the 3D total concentrations (Sič et al., 2016; El Amraoui et al., 2020), and in particular, all MOCAGE aerosol types are considered in the control vector. The choice of such control vector means that the vertical mass of aerosols should be constrained by the assimilation, but the size and type distribution will be proportional to the ones in the background. Assimilation of multiple wavelengths to constrain such variables has not been implemented yet. When assimilation is applied, it is done in cycled continuous approach: the analysis at a given instant is used as initial condition for the background one hour later. So the effect of assimilation of observations can propagate later in time.

\subsection{Observations and observation operators}

Several kinds of aerosol measurements are used in this study, either for assimilation in MOCAGE or for evaluation of the MOCAGE outputs. These observations are briefly presented here, together with the observation operators in MOCAGE.

\subsubsection{VACOS ash concentrations from MSG/SEVIRI}

The Volcanic Ash Cloud properties Obtained from SEVIRI algorithm (VACOS, Piontek et al., 2021b, a) derives volcanic ash coverage, ash optical thickness at $10.8 \mu \mathrm{m}$, mass column concentration, volcanic ash plume height and volcanic ash effective particle radius from data of the passive SEVIRI imager aboard the geostationary Meteosat Second Generation (MSG) satellite. It consists of four artificial neural networks (ANNs) trained with a set of SEVIRI brightness temperatures calculated for a multitude of typical atmospheric settings including liquid and ice water as well as volcanic ash clouds using radiative transfer calculations. The ash optical properties were calculated for different refractive indices to cover the large variability of generic petrological compositions of volcanic ash (Piontek et al., 2021c). Besides the SEVIRI brightness temperatures in the thermal infrared, VACOS uses auxiliary data, including the satellite viewing zenith angle, the skin temperature from a NWP model and clear sky brightness temperatures derived from SEVIRI images.

The capacity of VACOS data to detect ash and to estimate ash load during this eruption phase has been assessed by Plu et al. (2021). The overall conclusion is that VACOS can reliably applied to detect volcanic ash concentrations larger than 0.2 g.m ${ }^{-2}$. Morevover, the ash load estimates from VACOS from 13 to 20 May during the Eyjafjallajökull eruption are in rather good agreement with estimates in the literature. So VACOS data may be used as a reasonable reference data set for assessing and comparing the performance of different model outputs.

\subsubsection{MODIS AOD}

The retrieved aerosol optical depth (AOD) values (visible range) from the MODIS (Moderate-resolution Imaging Spectroradiometer) instruments onboard TERRA and AQUA (Levy and Hsu, 2015) can be assimilated in MOCAGE. Level-2 AOD at $550 \mathrm{~nm}$ (visible range) of the highest quality flag are considered: only pixels without any cloud contamination are kept. Since the MODIS AOD data have a higher horizontal resolution $(10 \mathrm{~km})$ than MOCAGE $\left(0.2^{\circ}\right)$, a super-observation approach is 
applied: at every hours and in every grid cell, the mean value of all the observations that fall in this grid cell is used as the input for the assimilation. Assimilation of MODIS AOD has effect on aerosol load locally, around the gridpoint where AOD is assimilated.

The observation operator for AOD in MOCAGE is described by Sič et al. (2016), except that the optical properties have been updated by Descheemaecker et al. (2019) since then. Volcanic ash optical properties are issued from Pollack et al. (1973).

\subsubsection{EARLINET lidar profiles}

The European Aerosol Research Lidar NETwork (EARLINET) has been established in 2000, and it is now one of the component of ACTRIS (Aerosol Clouds Trace gases Research Infrastructure). In 2010, EARLINET investigated the spatio-temporal distribution of the Eyjafjallajökull emitted ash plume over European continent thanks to the almost continuous observations performed at its 27 lidar stations distributed over Europe (Pappalardo et al., 2013). A devoted database reporting the geometrical and optical properties together with identification of the aerosol type for each of the aerosol layer observed during the whole related period is available at www.earlinet.org . During the 13-20 May period, a significant ash layer was detected over Cabauw and Hamburg lidar stations. The profiles of the aerosol backscatter coefficients at $532 \mathrm{~nm}$ (visible range) from these two lidars were used, to be assimilated in MOCAGE.

The aerosol lidar observation operator in MOCAGE is very similar to the one described by Janiskova and Stiller (2010), and it offers the possibility to assimilate different retrieved variables: backscatter coefficients, extinction coefficient or attenuated backscatter profiles. The aerosol optical properties are the same ones as for the AOD observation operator. The design and the performance of the lidar assimilation in MOCAGE have been described and assessed by El Amraoui et al. (2020).

\subsubsection{In-situ aircraft aerosol concentrations}

Schumann et al. (2011) reported many research flights over continental Europe and the North Sea, during which mass concentration of volcanic ash has been estimated. These measurements are meaningful as they are the only possible ones for direct estimates of ash concentration in 3 dimensions. However they are very sparse in space and time (see Fig. 1). They will be used in the present study for the evaluation of 3D-interpolated ash concentrations in the MOCAGE simulations.

\section{Representation of the emission and of the plume}

\subsection{Sensitivity of dispersed ash to the source term}

Many past studies have shown that ash dispersion is highly sensitive to the source term (Steensen et al., 2017b; Beckett et al., 2020), and that it is necessary to describe as much accurately as possible the mass eruption rate of the volcanic emission, the vertical distribution of ash aerosols in the column, and the size distribution. The complex processes and scarce difficult-to-make observations of the volcanic plume source have driven, in the first place, the development of empirical parametrisations, as the attempt to define the emission term in models. Such parametrisations relate the height of the eruption plume (as the parameter 
that can be readily be observed) and the mass of the eruption aerosols injected into the atmosphere. The regular and operational configuration of MOCAGE uses the Mastin et al. (2009) relation. Some of downsides of such parametrisations is that they do not address the question of the aerosol vertical distribution in the eruption column and they include only simplified description (if any) of the atmospheric conditions which influence the plume. Moreover, the height-mass relationship reflects a median behaviour based on past cases, and it is prone to important uncertainties from one case to the other.

In order to overcome such limitations of empirical parametrisations, other approaches simulate physical processes within the plume and their interaction with the atmosphere. The plume rise models get increasingly sophisticated and can provide estimations of eruption and plume source parameters, such as the ejected mass and the particle vertical size distribution. The 1-D cross-section averaged plume rise model FPLUME (Folch et al., 2016) has been introduced in MOCAGE, in order to assess the benefit of such plume rise model. FPLUME takes into account the effects of meteorological conditions on the thermodynamic of the plume, and of important physical processes like wet aggregation, air and particle entrainment and particle sedimentation. The FPLUME model is based on the turbulent buoyant plume theory, it resolves the height of an eruption plume from the eruption mass rate and the initial size distribution at the vent by solving the governing equations, and it also outputs as a result the plume mass vertical distribution and the height dependent particle size distribution for all levels within the plume. FPLUME implements the Costa et al. (2010) aggregation model. FPLUME in MOCAGE takes into account the wind influence (from the meteorological fields given in MOCAGE) on the plume shape and height.

Two MOCAGE simulations are done and compared: one with a parameterised empirical source term, the other with a resolved source term, for the Eyjafjallajökull eruption. In order to start the evaluation on 13 May from consistent initial ash concentrations MOCAGE fields, the emission starts from 9 May, 4 days before the period of evaluation. Plume height (Fig. 1) is issued from Arason et al. (2011), on which a simple pre-processing is applied: averaging is done at an hourly time step and at a 500m-accuracy height. This plume height information is used in both simulations to derive other source term parameters, as summarised in Table 1. In FPLUME, the MER is found by iterative solving (Folch et al., 2016) at every hour.

In FPLUME, the amount of rapidly removed particles from the plume is very variable and it depends on the eruption type, initial size distribution, eruption phase and external meteorological conditions. In the present case using FPLUME, the percentage of the mass eruption rate of the ash particles that is dispersed (i.e. which size falls into the fine ash classes and will be introduced in MOCAGE) varies from 0.1 to 5\%, depending on time and on the height. The effect of wet aggregation is rather low (less than 1\%), however. In the case of parameterised source-term, such variable effects cannot be produced with realistic conditions: an empirical ratio of mass eruption rate of $30 \%$ is applied to account for the proportion of ash that is sufficiently fine to be dispersed, and the aerosol size distribution is uniform in time and vertical (Table 1).

Time-altitude plots of the ash source term (Fig.2) points out how the different source terms can affect the MER and the vertical distribution of aerosol mass injection. Only fine ash that is then transported by MOCAGE is represented on the source term plots. The MER are generally in a similar order of magnitude for both simulations, however, in the phases when the plume height is around $5000 \mathrm{~m}$, the MER is generally higher for the FPLUME-resolved source term. When the plume reaches higher levels (around $8000 \mathrm{~m}$ ) on the contrary, the ash concentrations is generally higher for the parameterised source term than for the FPLUME-resolved one. For the FPLUME-resolved source term, the highest concentrations of ash are a layer of 
Table 1. Input parameters and assumptions for the two MOCAGE simulations: the empirical parametrisation source term, and the FPLUMEresolved source term

\begin{tabular}{|c|c|c|}
\hline & Empirical parametrisation & FPLUME resolving \\
\hline Plume top height & $\begin{array}{l}\text { Input parameter (as described in the text and in } \\
\text { Fig. } 1 \text { - right panel) }\end{array}$ & $\begin{array}{l}\text { Input parameter (as described in the text and in } \\
\text { Fig. } 1 \text { - right panel) }\end{array}$ \\
\hline $\begin{array}{l}\text { Physical assumptions of the } \\
\text { volcanic eruption }\end{array}$ & None (useless) & $\begin{array}{l}\text { Basaltic eruption type - Exit velocity (150 } \\
\left.\mathrm{m} . \mathrm{s}^{-1}\right)\end{array}$ \\
\hline $\begin{array}{l}\text { Total mass injected in } \\
\text { MOCAGE }\end{array}$ & $\begin{array}{l}30 \% \text { of the total mass emitted, as recommended } \\
\text { by Mastin et al. (2009) for medium-size silicic } \\
\text { eruptions }\end{array}$ & $\begin{array}{l}\text { Resolved by FPLUME (iterative mass solving, } \\
\text { as Folch et al. (2016)) }\end{array}$ \\
\hline Vertical mass profile & $\begin{array}{l}\text { Uniform (from volcano vent up to the plume } \\
\text { top) }\end{array}$ & Resolved by FPLUME \\
\hline Aerosol size distribution & $\begin{array}{l}\text { Uniform along the vertical, } 6 \text {-bins: } \\
10 \& 9,8,7,6,5,4 \text {, with respective mass frac- } \\
\text { tion (in \%) } 0.01,0.09,1.1,8.8,25,65\end{array}$ & Resolved by FPLUME along the vertical \\
\hline
\end{tabular}

a few hectometers just above the neutral buoyancy level, while for the parameterised source term, the ash is homogeneously distributed between the vent and the maximum plume height.

In order to illustrate the horizontal dispersion of the plume from the two source terms, the simulations are compared to VACOS ash total columns estimates, at three instants (Fig. 3). On 14 May at 06 UTC, a thin plume of ash has crossed the Atlantic and it reaches the Irish Sea and the Northern part of the British Isles. In both MOCAGE simulations, the plume has a realistic shape which goes in the right direction. On 16 May 2010 at 09 UTC, the plume has a similar direction but it is more horizontally extended than on 14 May. At both instants, all MOCAGE simulations follow the VACOS plume shape, but the simulated plumes are thicker than the one detected by VACOS. The parameterised source term generates also areas with ash (off the coast of Ireland for instance, on 16 May at 09 UTC) which are not obvious in VACOS. On 17 May 2010 at 20 UTC, the shape of both plumes look also similar, with differences however near the volcano source and in the North Sea. A localized ash packet aloft over Belgium and the Netherlands do not show up in the simulations. Overall, the FPLUME-resolved source term generates a plume that it less spread out, which is consistent with a more vertically confined emission (Fig. 2). Indeed, in presence of wind shear, different vertical distributions of ash can have large impact on the horizontal dispersion of ash load. Other diagnoses should confirm and justify this behaviour in a later section.

\subsection{Impact of the assimilation of MODIS AOD}

In order to evaluate the benefit of the assimilation of MODIS AOD for ash representation in MOCAGE, two additional simulations have been done, using respectively the two source terms. MODIS AOD data from Aqua and Terra, as described in Section. 2.3.2 have been assimilated in both simulations. Assimilation is done using the MOCAGE 3D-FGAT scheme at hourly 
step, continuously from the 10 May. An AOD observation error of 12\% is assumed in the assimilation. Fig. 4 illustrates the effect of assimilation of MODIS AOD, by comparison to the simulations without assimilation (Fig. 3), at three instants. On the simulations using the parameterised source term, the assimilation of MODIS AOD tends to limit the horizontal extent of the plume (on 16 May at 09 UTC: the ash plume off the Irish coast using the parameterised source term is mostly erased) and to locally decrease ash load (on 17 at 20 UTC: ash load over Iceland diminishes after assimilation). On the FPLUME source term simulation, the effect of MODIS assimilation on ash load is less obvious, which may suggests that there is no strong disagreement with AOD from this simulation against MODIS measurements. To summarize, the effect of the assimilation of MODIS on the horizontal extent of the plume is higher on the simulation with the parameterised source-term than on the FPLUME one. The effect of assimilation is mainly to reduce ash load locally. In the following section, some metrics are shown to compare the different simulations and address the impact of MODIS assimilation.

\subsection{Mutual benefit of source terms and of assimilation}

The evaluation of the different simulations are done against VACOS measurements, using a similar approach as the one shown by Plu et al. (2021). VACOS and MOCAGE data are regridded at $0.2^{\circ}$ resolution on the domain shown in Fig. 1. Fig. 5 provides some diagnoses about the capacity of detection of ash by MOCAGE simulations compared to the VACOS measurements: number of contaminated gridpoints (concentration value above $0.2 \mathrm{~g} \cdot \mathrm{m}^{-1}$ for VACOS and all simulations, concentration values at the contaminated gridpoints, hits (the number of contaminated gridpoints in both MOCAGE and VACOS), false alarms (number of gridpoints that are contaminated in MOCAGE and not in VACOS), for every MOCAGE simulations. Detection is done on the same $0.2^{\circ}$-resolution grid, but the gridpoints where VACOS ash detection (due to clouds for instance) was not possible are excluded from the analysis (even for the model outputs).

The time evolution of the number of contaminated gridpoints follows similar trends as the eruption evolves; for instance a maximum number of contaminated gridpoints is obvious some hours after the maximum phase of eruption (18 May at 00 UTC). However, the number of contaminated gridpoints for the model simulations is significantly higher (about twice higher) than for the VACOS estimates. Examination of Fig. 3 helps to understand the respective capacities of ash detection by VACOS retrievals and by the models. The contaminated areas in the model outputs and in VACOS look in rather good agreement. However, the model contaminated areas are continuous, while the VACOS data spots out the most contaminated areas.

The detection capacity of contaminated gridpoints is rather good for all models (third raw of Fig. 5), and there is not much differences between the model simulations. During the first phase of the eruption (from 13 to 16 May), a noticeable, although low, number of gridpoints are not detected as contaminated by the model simulations. Afterwards all contaminated gridpoints are correctly detected by simulations.

Consistently with the evidence that the contaminated gridpoints in VACOS are lower than in the models, there is a high number of false alarms in all model simulations. However, it is noticeable that the number of false alarms is significantly lower for the FPLUME simulation than for the other source term. This is consistent with the fact that FPLUME generates a more condensed plume along the horizontal dimension (Fig. 3), remaining in better agreement with the observed plume. Overall the 
assimilation of MODIS tends to diminish the false alarms without changing noticeably the detected area of ash. The impact of MODIS assimilation is lower for the simulation with FPLUME source term than for the parameterised source term.

The Fraction Skill Score (FSS) is a meaningful metric to assess the performance of volcanic ash dispersion simulations, by determining the scale over which a simulation has skill (Harvey and Dacre, 2016) for the location of ash plumes along the horizontal dimensions. The implementation and use of FSS in this study is similar to the one presented by Plu et al. (2021). It is calculated as:

$$
F S S(r)=1-\frac{\sum_{j=1}^{N}\left[O_{j}(r)-M_{j}(r)\right]^{2}}{\sum_{j=1}^{N}\left[O_{j}^{2}(r)+M_{j}^{2}(r)\right]}
$$

with $N$ being the total number of grid points in the verification area, and $M_{j}(r)$ and $O_{j}(r)$ being the fractions of contaminated grid points within the circle of radius $r$ around point $j$, for the model (a MOCAGE simulation) and the observations (VACOS reference), respectively. A model has skill when the FSS at a given scale is above 0.5; the FSS can also be used to compare simulations: the higher FFS, the better. On Fig. 6, the FSS is shown for distance radius of $50 \mathrm{~km}, 200 \mathrm{~km}$ and $500 \mathrm{~km}$.

The FSS evolves in time following similar trends for all model simulations. For a distance of $50 \mathrm{~km}$, the FSS is not always above 0.5 . When the radius increases, the score performs better: for a radius of $500 \mathrm{~km}$, the FSS is above 0.5 for all simulations (except on the 19 May, when the number of VACOS valid gridpoints vanishes). It is noticeable that the FPLUME simulation has always better scores than the other source term. Besides, the assimilation of MODIS does not change the score at all times, but when it does, it is in a way of improvement, although slighter than the difference between FPLUME and the parameterised source term. This FSS metric confirms that the location of the plume using FPLUME is more appropriate than the other source term and that the assimilation of MODIS improves the location of the plume, but with an impact that is lower and less permanent.

\section{Representation of the concentrations above Europe}

In the previous section, the horizontal extent of the plume has been assessed for different numerical simulations. It has been shown that the FPLUME source term provides a better horizontal extension of the plume. However, the concentrations along the vertical dimension are an information that is also needed by air authorities. Besides, Plu et al. (2021) showed that the vertical distribution of ash is generally biased in source terms and dispersion models, at least on this case study. The purpose of this section is to assess simulations with regards to ground-based lidar measurements and to aircraft in-situ observations, between 17 May and 19 May, when the plume approaches and then spreads over continental Europe. Lidar observations are assimilated in the FPLUME MOCAGE simulation, and the benefit of such assimilation is also assessed.

\subsection{Assimilation of ground-based lidar profiles}

Backscatter coefficients at $532 \mathrm{~nm}$ from the Cabauw and Hamburg lidars have been used in this study. Signature of ash is obvious (Fig. 7, left panels) in these profiles at different instants: backscatter maxima may be seen around 4km on 17 at 15 UTC at Cabauw, around $3 \mathrm{~km}$ and $4.5 \mathrm{~km}$ on 17 at 15 UTC at Hamburg, and around $4.5 \mathrm{~km}$ on 18 at 9 UTC at Cabauw. The 
aerosol mask analysis develloped for the aerosol lidar observations (Mona et al., 2012) identified as volcanic such lofted layers, but also as mixed volcanic ash-local aerosol content in the lowest aerosol layers below the top of atmospheric boundary layer (Pappalardo et al., 2013) . At the same instant, the MOCAGE direct simulation (based on FPLUME source term, without assimilation of MODIS) shows different profiles of backscatter coefficient (middle column) and of ash concentrations (left column): volcanic ashes reach rather high values (from 20 to $150 \mu \mathrm{g} \cdot \mathrm{m}^{-3}$ ), but the highest concentrations may be found in the lower levels, around 1 to $2 \mathrm{~km}$ altitude. These high concentrations in the lowest levels may be due to some shortcomings in the representation of vertical processes in the model (Plu et al., 2021).

The assimilation of lidar backscatter profiles in MOCAGE is done using 3D-VAR, at a hourly step, from 17 May at 00 UTC until 19 May at 00UTC. Assimilation is done continuously: the background at hour $\mathrm{H}$ is the 1-hour forecast starting from the analysis at hour $\mathrm{H}-1$. The assimilation procedure is described in Section 2.2, and the following parameters apply:

- the square-root of the background error variance is $50 \mu \mathrm{g} \cdot \mathrm{m}^{-3}$,

- the horizontal correlation length is $1^{\circ}$ (roughly half of the distance between Cabauw and Hamburg),

- the vertical correlation length is two model levels.

The assimilation of lidar backscatter profiles requires some pre-processing, due to the fact that the vertical resolution of EARLINET backscatter profiles is much finer $(100 \mathrm{~m})$ than the MOCAGE vertical resolution. In order to avoid inconsistencies in the assimilation process, the lidar profiles are regridded at a resolution similar to MOCAGE. Two different datasets are prepared for assimilation:

- "EARLINET mean": the lidar value is the mean of lidar backscatter coefficient between two MOCAGE levels,

- "EARLINET max": the lidar value is the maximum of lidar backscatter coefficient between tow MOCAGE levels.

Such values ("mean" and "max") have been chosen in order to assess the sensitivity of the assimilation to the pre-processing of lidar profiles. Some high values of backscatter coefficients can be seen in the lowest levels, which is probably not a signature of volcanic ash only, but as obtained by the detailed analysis of the lidar observations is rather the result of the mixing between volcanic ash and continental aerosol pollution. Such values are kept for assimilation, and the MOCAGE control vector includes all the types of aerosols that the model is able to represent (Guth et al., 2016). In the assimilation, the square-root of the observation error variance is $10 \%$.

The profiles corresponding to the assimilated data (Fig. 7) shows how the assimilation process behaves. The peaks of lidar backscatter coefficients at altitudes between 2 and $5 \mathrm{~km}$ correspond to the location of ash cloud. The profile of ash in MOCAGE direct run does not show a local maximum at these locations, but rather a quasi-uniform distribution of ash between the surface and $6 \mathrm{~km}$ (at Cabauw), or a peak just below 2km (at Hamburg), consistently with the results of Plu et al. (2021). The simulations using assimilation of lidar profiles increase the concentrations of ash at the right altitude range. However, the peaks of backscatter coefficients and of ash concentration in the assimilated runs are much smoother along the vertical compared to the assimilated lidar profiles. It is also obvious that the backscatter coefficients after assimilation (around $0.5 \mathrm{~m}^{-1} . \mathrm{sr}^{-1}$ ) $\mathrm{are}$ 
still much lower than the observation values that are assimilated (around $2 \mathrm{~m}^{-1} \cdot \mathrm{sr}^{-1}$ ), which may be due to weight of the model background, to the model resolution and to the vertical error correlation. The assimilation of mean lidar data or of max lidar data looks similar in shape, but highly different in amplitude.

The assimilated profiles on 18 May at 9 UTC over Cabauw look more consistent with the lidar profile than on 17 May. A possible explanation can be that the ash cloud has been assimilated continuously and longer in time on 18 May, at a time when the corrections have been accumulated and propagated in time and in space.

The assimilation of lidar backscatter profiles has also a large effect on ash concentrations in the boundary layer. On 17 May, assimilation increases drastically the ash concentrations in the boundary layer. The increments of ash are linked to preexisting proportion of ash in the control vector, and the assimilation process assumes this proportion to be kept unchanged at every gridpoint. If the proportion of ash in MOCAGE is too high, then the correction increases too much ash with regards to other aerosols. One possibility is that there is a negative bias of non-ash aerosols in MOCAGE, which has a double detrimental effect: it generates a negative bias of backscatter coefficients, and it increases the proportion of ash in the boundary layer. On 18 May on the contrary, ash concentrations are lower after assimilation in the boundary layer.

\subsection{Evaluation against in-situ aircraft measurements}

During the period of the study, airborne measurements have been reported in the literature. Schumann et al. (2011) reported in-situ estimates of 3D ash concentrations above the North Sea, Germany, and the Netherlands on 13, 16, 17, and 18 May. Such aircraft measurements provide estimates of the ash concentrations at different levels, although with high uncertainty margins. In order to evaluate the benefit of assimilation of lidar profiles, comparisons of ash concentrations at the MOCAGE levels that fit the altitude of the aircraft measurements are provided.

The first flight considered is one over "North Sea", on 17 May around 16 UTC. The aircraft flew in a layer of ash between 3.2 and $6.3 \mathrm{~km}$, where concentrations of ash between 105 and $283 \mu \mathrm{g} \cdot \mathrm{m}^{-3}$ were measured. In the MOCAGE levels at this instant, the assimilation of lidar data increases the concentration of ash, as shown on Fig. 8. The flight is quite close to the Cabauw lidar, and as shown in Fig. 7, the result of assimilation still leads to underestimation of ash concentrations. The core of highest concentrations of ash in the model are still located north to the flight measurements.

The ash concentrations in MOCAGE corresponding to two flights over continental Europe on 18 May around 10 UTC are examined on Fig. 9. The flight around Stuttgart measured ash concentrations between 16 and $38 \mu \mathrm{g} . \mathrm{m}^{-} 3$ at altitude $5.2 \mathrm{~km}$. In the MOCAGE direct simulation (without assimilation), the plume has a thin shape and the concentrations around the flight (upper-panel of Fig. 9) are below $25 \mu \mathrm{g} \cdot \mathrm{m}^{-}$3. After assimilation, the MOCAGE simulations shows a clear increase of ash concentrations and of the extent of the plume, that covers a larger part of Germany. The ash concentration values around the flight are closer to the measurements after assimilation.

The flight around Hamburg measured ash concentrations between 38 and $93 \mu \mathrm{g} \cdot \mathrm{m}^{-} 3$ at altitude $3.1 \mathrm{~km}$. Like for the Stuttgart flight, the assimilation increases the concentrations of ash and the extent of the plume. The MOCAGE ash concentrations near Hamburg are around $25 \mu \mathrm{g} \cdot \mathrm{m}^{-} 3$ in the direct run, around $25 \mu \mathrm{g} \cdot \mathrm{m}^{-} 3$ when mean lidar profiles are assimilated and around $75 \mu \mathrm{g} \cdot \mathrm{m}^{-} 3$ when maximum lidar profiles are assimilated. 

altitudes 4 to $5 \mathrm{~km}$. The MOCAGE runs with assimilation increases also the values of ash in this region. Although there is no quantitative estimate of ash concentrations, the range of values after assimilation over the Po Valley looks in better agreement than without assimilation.

The assimilation of lidar data from two points where an ash plume enters Europe induces corrections of ash concentrations as far as several hundreds of km away over Europe. Although the flight measurements are sparse and have large error margins, the model estimates after assimilation look more realistic than before assimilation. It is also noticeable that the correction by lidar cumulates in time: while the correction is rather low when the plume reaches Europe (17 May at 16UTC), it is larger in extent and intensity several hours after (18 at 10UTC). This may be due to the assimilation procedure, which has been done using a continuous hourly configuration.

\section{Conclusions}

This study investigated the benefit for the 3D representation of volcanic ash of a resolved source term and of the assimilation of different observations datasets, using the MOCAGE model. The main findings are:

- the use of a resolved source term instead of a parameterised source term induces a more realistic representation of the horizontal dispersion of the ash plume,

- a positive impact of the assimilation of MODIS AOD on the horizontal dispersion the plume has been shown, but this effect is rather low and local, compared to source term improvement,

- the continuous assimilation of lidar profiles from two ground-based stations improves the vertical distribution of ash and helps to reach realistic values of ash concentrations.

As shown during the EUNADICS-AV project and demonstrations (Hirtl et al., 2019), a reliable representation of volcanic ash concentrations is needed to manage air traffic. The assimilation of lidar information is a way forward to tackle the tendency of model simulations to dilute ash along the vertical (Plu et al., 2021). Future work on other cases should confirm the results of the present study, before being able to apply them in an operational context.

A better resolved source term should have positive impacts on the vertical distribution of ash, and also on its grain size distribution. A perspective would be to assess how much these effects can change the optical properties of ash clouds and so the assimilation of data downstream. A better source term can also be beneficial as a better a priori for inversion of satellite column ash load.

The rather low impact of the assimilation of MODIS AOD on this case could be due to different reasons, one of them being the revisit time of polar-orbiting satellites. The assimilation of AOD from geostationary satellites, such as MTG in the future (Descheemaecker et al., 2019), by increasing the time frequency of the measurements, could increase the impact in space and time. 
The present study is the first one, to our knowledge, that assesses the impact of continuous assimilation of ground-based lidars on a volcanic ash cloud. When the ash cloud reaches continental Europe, there is a clear benefit of assimilating lidar profiles to better constrain the concentrations of ash and their vertical distribution. Since 2010, there has been an increase of the density of lidars in Europe, and operational networks have been put in place (operational lidars in France and UK, EUMETNET E-PROFILE network). Additionally the number of advanced lidars running continuously within ACTRIS/EARLINET has also increased. Based on our results, we can expect that, these data, if assimilated in aerosol transport models, can be highly beneficial for the 3D representation of ash concentrations. Still, some work needs to be done. First, the processing of lidar data as input for assimilation requires some work: which lidar variable would be the most suited for assimilation? How to aggregate the values on a vertical scale to take into account the different resolutions of model and measurements? Second, the tuning of assimilation algorithms, depending on the input data, needs also to be done. In order to tune and achieve good quality assimilation of lidar for ash monitoring, there is a need for more observations on volcanic ash clouds, particularly for sampling the concentration of ash in-situ. The rarity of volcanic eruptions could be mitigated by studying volcanic clouds worldwide.

Author contributions. BS implemented FPLUME in MOCAGE. BS and EE designed the assimilation of aerosols. GB analysed the case study, designed the simulations and developed some diagnostics. LEA made some simulations. BJ and JG developed some aerosol components and helped with running MOCAGE. LM provided interpretation of EARLINET observations and lidar assimilation results. MP developed and generated most of the results, conducted their analysis and was the main writer.

Competing interests. The authors do not have competing interests.

Acknowledgements. This work has been conducted within the framework of the EUNADICS-AV project, which has received funding from the European Union's Horizon 2020 research programme for Societal challenges - smart, green and integrated transport under grant agreement no. 723986. The authors thank A. Folch for having provided the FPLUME model for implementation in MOCAGE. 


\section{References}

Arason, P., Petersen, G. N., and Bjornsson, H.: Observations of the altitude of the volcanic plume during the eruption of Eyjafjallajökull, April-May 2010, Earth System Science Data, 3, 9-17, https://doi.org/10.5194/essd-3-9-2011, https://www.earth-syst-sci-data.net/3/9/ $2011 /, 2011$.

Beckett, F. M., Witham, C. S., Leadbetter, S. J., Crocker, R., Webster, H. N., Hort, M. C., Jones, A. R., Devenish, B. J., and Thomson, D. J.: Atmospheric Dispersion Modelling at the London VAAC: A Review of Developments since the 2010 Eyjafjallajökull Volcano Ash Cloud, Atmosphere, 11, 1-26, https://doi.org/10.3390/atmos11040352, 2020.

Bugliaro, L., Piontek, D., Graf, K., Schmidl, M., Kox, S., Mayer, B., Müller, R., and Gasteiger, J.: Volcanic ash remote sensing with MSG/SEVIRI using an artificial neural network, tbc, 2021.

Clarkson, R. J., Majewicz, E. J. E., and Mack, P.: A re-evaluation of the 2010 quantitative understanding of the effects volcanic ash has on gas turbine engines, Proc IMechE Part G: J Aerospace Engineering, 230, 2274-2291, https://doi.org/10.1177/0954410015623372, 2016.

Costa, A., Folch, A., and Macedonio, G.: A model for wet aggregation of ash particles in volcanic plumes and clouds: 1. Theoretical formulation, J. Geophys. Res. B: solid Earth, 115, B09 201, https://doi.org/10.1029/2009JB007175, 2010.

Descheemaecker, M., Plu, M., Marécal, V., Claeyman, M., Olivier, F., Aoun, Y., Blanc, P., Wald, L., Guth, J., Sič, B., Vidot, J., Piacentini, A., and Josse, B.: Monitoring aerosols over Europe: an assessment of the potential benefit of assimilating the VIS04 measurements from the future MTG/FCI geostationary imager, Atmospheric Measurement Techniques, 12, 1251-1275, https://doi.org/10.5194/amt-12-12512019, https://www.atmos-meas-tech.net/12/1251/2019/, 2019.

El Amraoui, L., Sič, B., Piacentini, A., Marécal, V., Attié, J.-L., and Frebourg, N.: Aerosol data assimilation in the chemical transport model MOCAGE during the TRAQA/ChArMEx campaign: Lidar observations, Atmospheric Measurement Techniques Discussions, 2020, 1-35, https://doi.org/10.5194/amt-2019-482, 2020.

Folch, A., Costa, A., and Macedonio, G.: FPLUME-1.0: An integral volcanic plume model accounting for ash aggregation, Geosci. Model Dev., 9, 431-450, https://doi.org/10.5194/gmd-9-431-2016, 2016.

Guth, J., Josse, B., Marécal, V., Joly, M., and Hamer, P.: First implementation of secondary inorganic aerosols in the MOCAGE version R2.15.0 chemistry transport model, Geosci. Model Dev., 9, 137-160, https://doi.org/10.5194/gmd-9-137-2016, 2016.

Harvey, N. J. and Dacre, H. F.: Spatial evaluation of volcanic ash forecasts using satellite observations, Atmospheric Chemistry and Physics, 16, 861-872, https://doi.org/10.5194/acp-16-861-2016, 2016.

Hirtl, M., Stuefer, M., Arnold, D., Grell, G., Maurer, C., Natali, S., Scherllin-Pirscher, B., and Webley, P.: The effects of simulating volcanic aerosol radiative feedbacks with WRF-Chem during the Eyjafjallajökull eruption, April and May 2010, Atmos. Environ., 198, 194-206, https://doi.org/10.1016/j.atmosenv.2018.10.058, 2019.

IATA: Annual Report, Tech. rep., International Air Transport Association, https://www.iata.org/about/Documents/IATAAnnualReport2010. pdf, 2010.

ICAO: Volcanic Ash Contingency Plan - European and North Atlantic Regions, Tech. rep., International Civil Aviation Organisation, https: //www.icao.int/EURNAT/EURandNATDocuments/EUR+NATVACP.pdf, 2016.

Janiskova, M. and Stiller, O.: Development of strategies for radar and lidar data assimilation, Tech. Rep. 2010:WP-3100 contract 15576/07/NL/CB, ECMWF, https://www.ecmwf.int/node/10162, 2010.

Krumbein, W. C.: Size frequency distributions of sediments, J. Sediment. Res., 4, 65-67, 1934. 
https://doi.org/10.5194/nhess-2021-97

Preprint. Discussion started: 30 March 2021

(c) Author(s) 2021. CC BY 4.0 License.

Levy, R. and Hsu, C.: MODIS Atmosphere L2 Aerosol Product. NASA MODIS Adaptive Processing, https://doi.org/10.5067/MODIS/MYD04_L2.061,10.5067/MODIS/MOD04_L2.061, 2015.

Massart, S., Clerbaux, C., Cariolle, D., Piacentini, A., Turquety, S., and Hadji-Lazaro, J.: First steps towards the assimilation of IASI ozone data into the MOCAGE-PALM system, Atmospheric Chemistry and Physics, 9, 5073-5091, https://doi.org/10.5194/acp-9-5073-2009, 2009.

Mastin, L., Guffanti, M., Servranckx, R., Webley, P., Barsotti, S., Dean, K., Durant, A., Ewert, J., Neri, A., Rose, W., et al.: A multidisciplinary effort to assign realistic source parameters to models of volcanic ash-cloud transport and dispersion during eruptions, Journal of Volcanology and Geothermal Research, 186, 10-21, 2009.

Mastin, L. G.: A user-friendly one-dimensional model for wet volcanic plumes, Geochemistry Geophysics Geosystems, 8, Q03 014, https://doi.org/10.1029/2006GC001455, 2007.

Mona, L., Amodeo, A., D’Amico, G., Giunta, A., Madonna, F., and Pappalardo, G.: Multi-wavelength Raman lidar observations of the Eyjafjallaj $\sqrt{ } \partial$ kull volcanic cloud over Potenza, southern Italy, Atmospheric Chemistry and Physics, 12, 2229-2244, https://doi.org/10.5194/acp-12-2229-2012, https://acp.copernicus.org/articles/12/2229/2012/, 2012.

Pappalardo, G., Mona, L., D’Amico, G., Wandinger, U., Adam, M., Amodeo, A., Ansmann, A., Apituley, A., Alados Arboledas, L., Balis, D., Boselli, A., Bravo-Aranda, J. A., Chaikovsky, A., Comeron, A., Cuesta, J., De Tomasi, F., Freudenthaler, V., Gausa, M., Giannakaki, E., Giehl, H., Giunta, A., Grigorov, I., Groß, S., Haeffelin, M., Hiebsch, A., Iarlori, M., Lange, D., Linné, H., Madonna, F., Mattis, I., Mamouri, R.-E., McAuliffe, M. A. P., Mitev, V., Molero, F., Navas-Guzman, F., Nicolae, D., Papayannis, A., Perrone, M. R., Pietras, C., Pietruczuk, A., Pisani, G., Preißler, J., Pujadas, M., Rizi, V., Ruth, A. A., Schmidt, J., Schnell, F., Seifert, P., Serikov, I., Sicard, M., Simeonov, V., Spinelli, N., Stebel, K., Tesche, M., Trickl, T., Wang, X., Wagner, F., Wiegner, M., and Wilson, K. M.: Four-dimensional distribution of the 2010 Eyjafjallajökull volcanic cloud over Europe observed by EARLINET, Atmospheric Chemistry and Physics, 13, 4429-4450, https://doi.org/10.5194/acp-13-4429-2013, 2013.

Piontek, D., Bugliaro, L., Kar, J., Schumann, U., Marenco, F., Plu, M., and Voigt, C.: A new Volcanic Ash Retrieval for MSG-SEVIRI based on Artificial Neural Networks: 2. Validation, tbd, 2021a.

Piontek, D., Bugliaro, L., Schmidl, M., Zhou, D., and Voigt, C.: A new Volcanic Ash Retrieval for MSG-SEVIRI based on Artificial Neural Networks: 1. Development, tbd, 2021 b.

Piontek, D., Hornby, A., Voigt, C., Bugliaro, L., and Gasteiger, J.: Determination of complex refractive indices and optical properties of volcanic ashes in the thermal infrared based on generic petrological compositions, J. Volcanol. Geotherm. Res., 411, 107174 , https://doi.org/10.1016/j.jvolgeores.2021.107174, http://www.sciencedirect.com/science/article/pii/S0377027321000032, 2021c.

Plu, M., Scherllin-Pirscher, B., Arias, D. A., Baro, R., Bigeard, G., Bugliaro, L., Carvalho, A., Amraoui, L. E., Eschbacher, K., Hirtl, M., Maurer, C., Mulder, M. D., Piontek, D., Robertson, L., Rokitansky, C.-H., Zobl, F., and Zopp, R.: A tailored multi-model ensemble for air traffic management: Demonstration and evaluation for the Eyjafjallajökull eruption in May 2010, Nat. Hazards Earth Sys. Sci., 2021.

Pollack, J. B., Toon, O. B., and Khare, B. N.: Optical properties of some terrestrial rocks and glasses, Icarus, 19 , $372-389$, https://doi.org/https://doi.org/10.1016/0019-1035(73)90115-2, 1973.

Schumann, U., Weinzierl, B., Reitebuch, O., Schlager, H., Minikin, A., Forster, C., Baumann, R., Sailer, T., Graf, K., Mannstein, H., Voigt, C., Rahm, S., Simmet, R., Scheibe, M., Lichtenstern, M., Stock, P., Rüba, H., Schäuble, D., Tafferner, A., Rautenhaus, M., Gerz, T., Ziereis, H., Krautstrunk, M., Mallaun, C., Gayet, J.-F., Lieke, K., Kandler, K., Ebert, M., Weinbruch, S., Stohl, A., Gasteiger, J., Groß, S., Freudenthaler, V., Wiegner, M., Ansmann, A., Tesche, M., Olafsson, H., and Sturm, K.: Airborne observations of the Eyjafjalla volcano 
https://doi.org/10.5194/nhess-2021-97

Preprint. Discussion started: 30 March 2021

(c) Author(s) 2021. CC BY 4.0 License.

ash cloud over Europe during air space closure in April and May 2010, Atmos. Chem. Phys., 11, 2245-2279, https://doi.org/10.5194/acp11-2245-2011, 2011.

Sič, B., El Amraoui, L., Piacentini, A., Marécal, V., Emili, E., Cariolle, D., Prather, M., and Attié, J.-L.: Aerosol data assimilation in the chemical transport model MOCAGE during the TRAQA/ChArMEx campaign: aerosol optical depth, Atmospheric Measurement Techniques, 9, 5535-5554, 2016.

Steensen, B. M., Kylling, A., Kristiansen, N. I., and Schulz, M.: Uncertainty assessment and applicability of an inversion method for volcanic ash forecasting, Atmospheric Chemistry and Physics, 17, 9205-9222, https://doi.org/10.5194/acp-17-9205-2017, 2017a.

Steensen, B. M., Schulz, M., Wind, P., Valdebenito, A. M., and Fagerli, H.: The operational eEMEP model version 10.4 for volcanic SO 2 and ash forecasting, Geoscientific Model Development, 10, 1927-1943, https://doi.org/10.5194/gmd-10-1927-2017, 2017b.

Stohl, A., Prata, A. J., Eckhardt, S., Clarisse, L., Durant, A., Henne, S., Kristiansen, N. I., Minikin, A., Schumann, U., Seibert, P., Stebel, K., Thomas, H. E., Thorsteinsson, T., Tørseth, K., and Weinzierl, B.: Determination of time- and height-resolved volcanic ash emissions and their use for quantitative ash dispersion modeling: the 2010 Eyjafjallajökull eruption, Atmos. Chem. Phys., 11, 4333-4351, https://doi.org/10.5194/acp-11-4333-2011, 2011. 
https://doi.org/10.5194/nhess-2021-97

Preprint. Discussion started: 30 March 2021

(c) Author(s) 2021. CC BY 4.0 License.
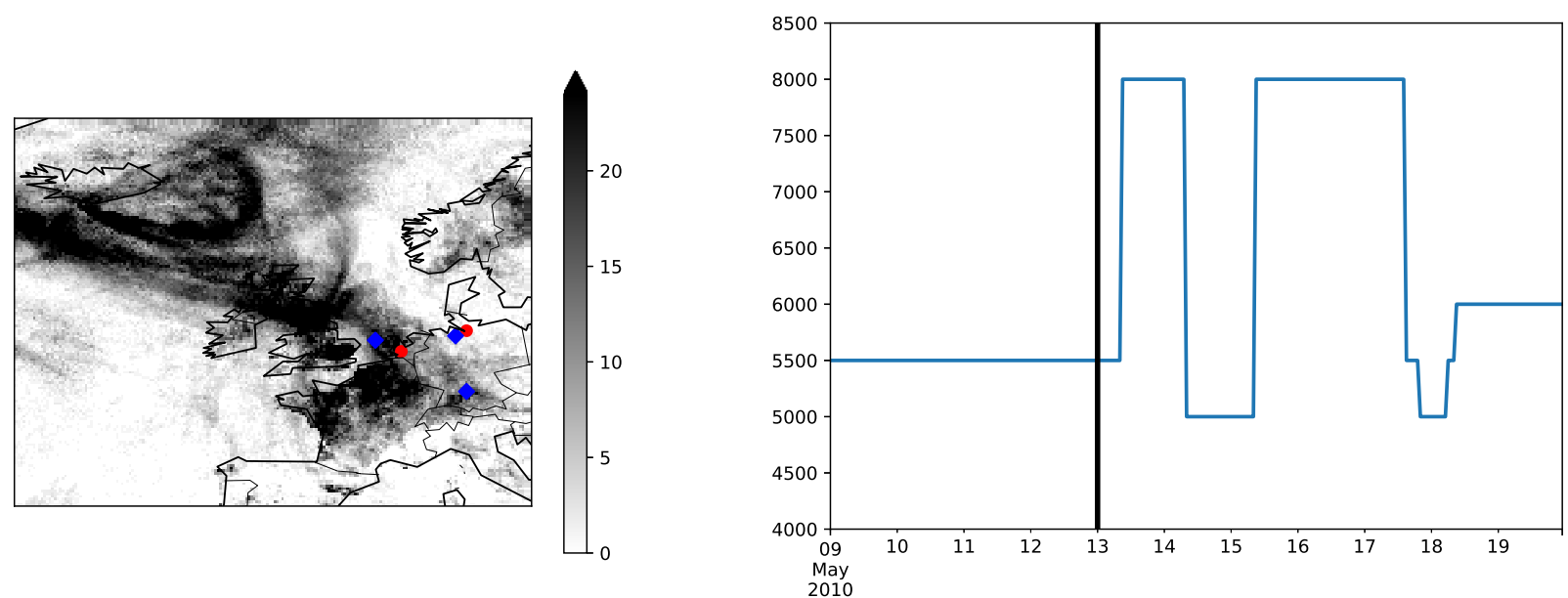

Figure 1. Left panel: Map of the number of gridpoints that are contaminated by volcanic ash according to the observations (grey shadings) from 13 to 20 May 2010. Diagnostics and scores are computed in this domain. The red dots indicate the Cabauw and Hamburg lidars. The blue dots refer to the location of the flight legs where aerosol measurements are available. Right panel: emission height profile (m above sea level) used as input of the source term. The emission starts on 9 May in the model, but the evaluation of simulations starts on 13 May (vertical line). 

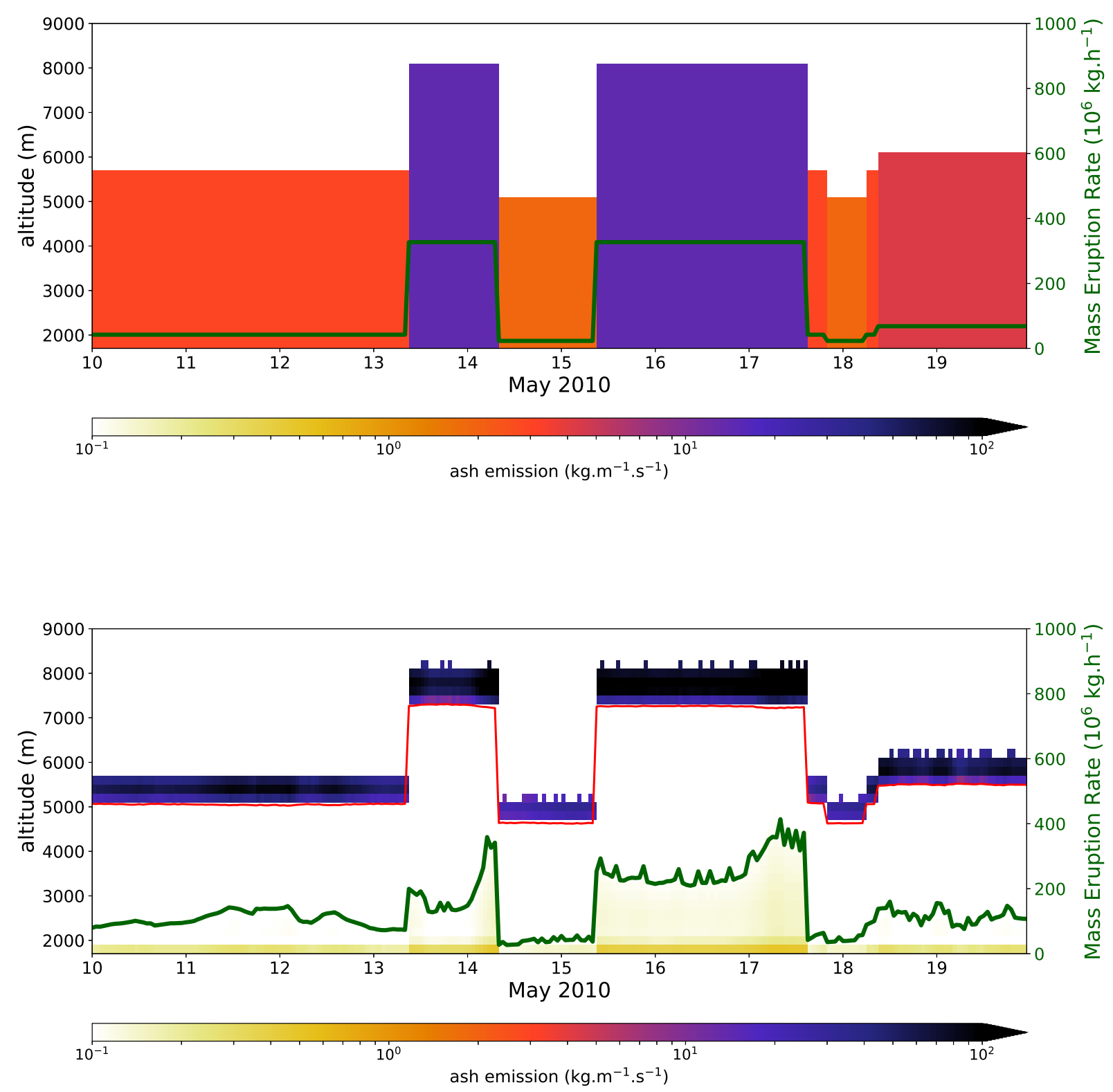

Figure 2. Comparison of MOCAGE ash source terms (unit: $\mathrm{kg} \cdot \mathrm{m}^{-1} \cdot \mathrm{s}^{-1}$ ), as a function of time (horizontal axis) and altitude (left vertical axis), from 10 to 19 May 2010, using the parameterised source term (upper panel) and the source term resolved by FPLUME (bottom panel). The green lines and right vertical axis refer to the Mass Eruption Rate issued from the two source terms respectively. In the bottom plot, the red line shows the neutral buoyancy level that is computed in FPLUME. 

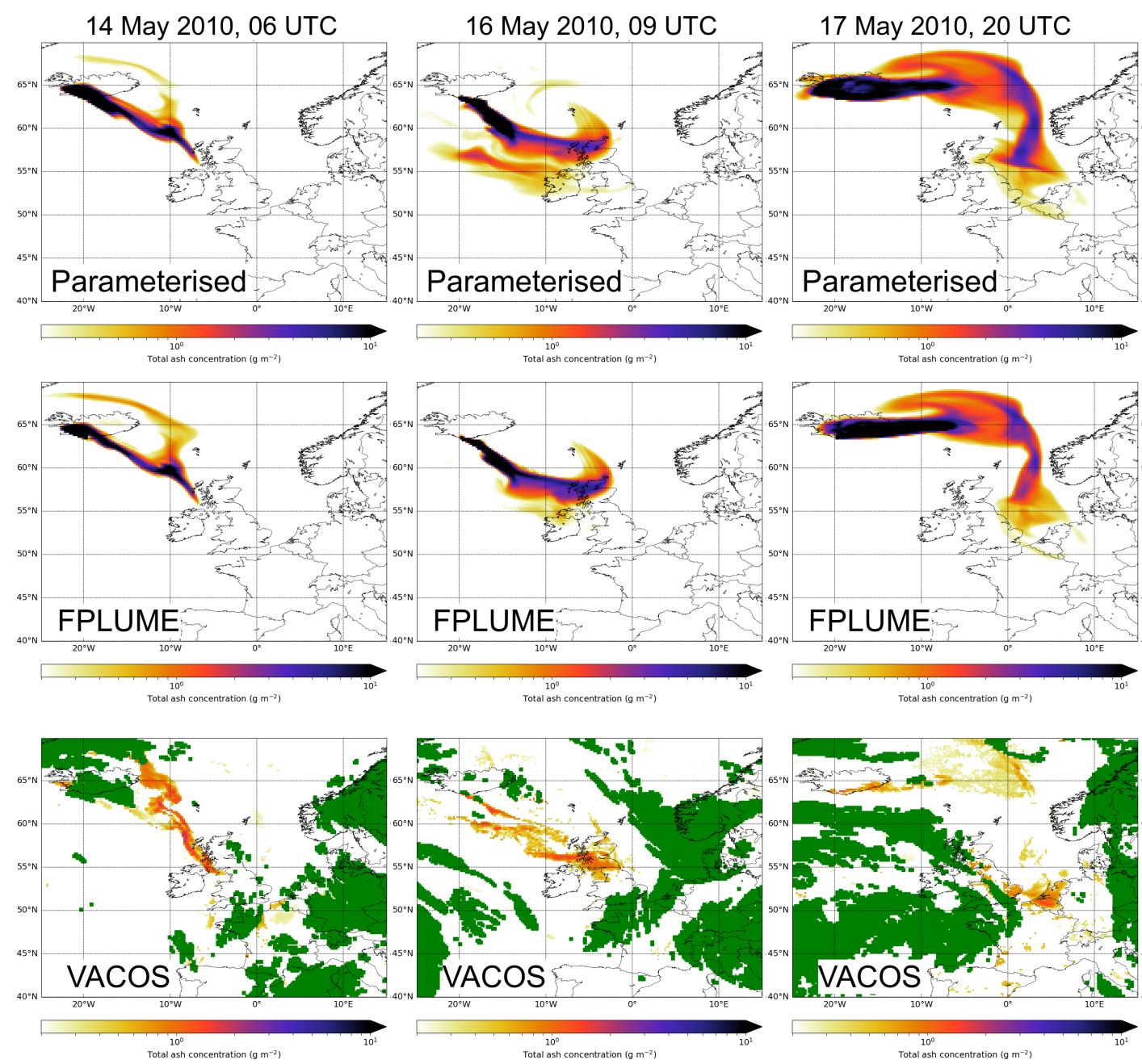

Figure 3. Total ash column simulated by MOCAGE using the parameterised source term (upper panels) and the source term resolved by FPLUME (middle panels), and estimated by the VACOS retrievals (lower panels), on 14 May 2010 at 06 UTC (left panels), on 16 May 2010 at 09 UTC (middle panels) and on 17 May 2010 at 20 UTC (right panels). The green colour refer to gridpoints where the ash retrieval could not be done (due to the presence of clouds, for instance). 

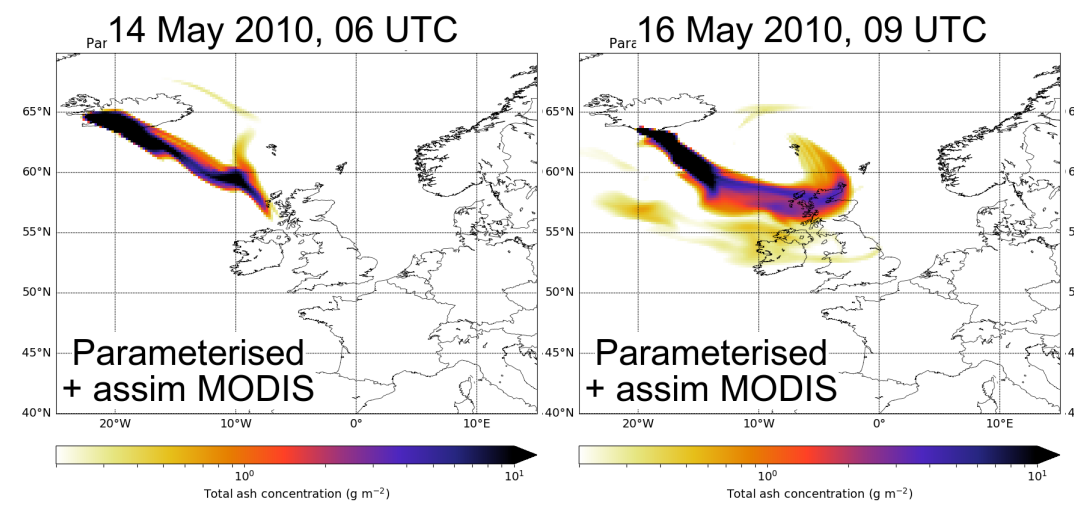

17 May 2010, 20 UTC
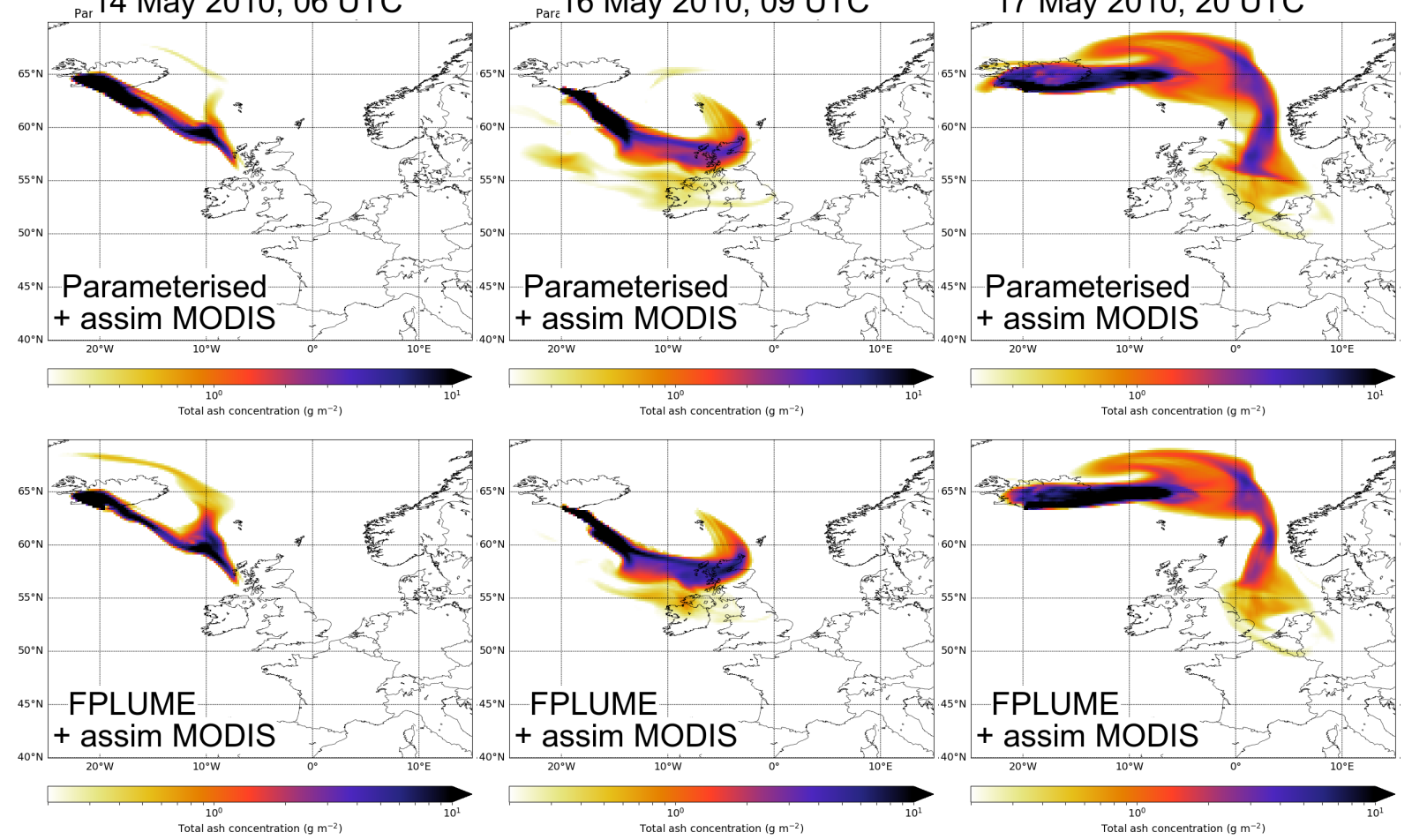

Figure 4. Same legend as Figure 3, for MOCAGE simulations after assimilation of TERRA and AQUA MODIS AOD. 
https://doi.org/10.5194/nhess-2021-97

Preprint. Discussion started: 30 March 2021

(c) Author(s) 2021. CC BY 4.0 License.
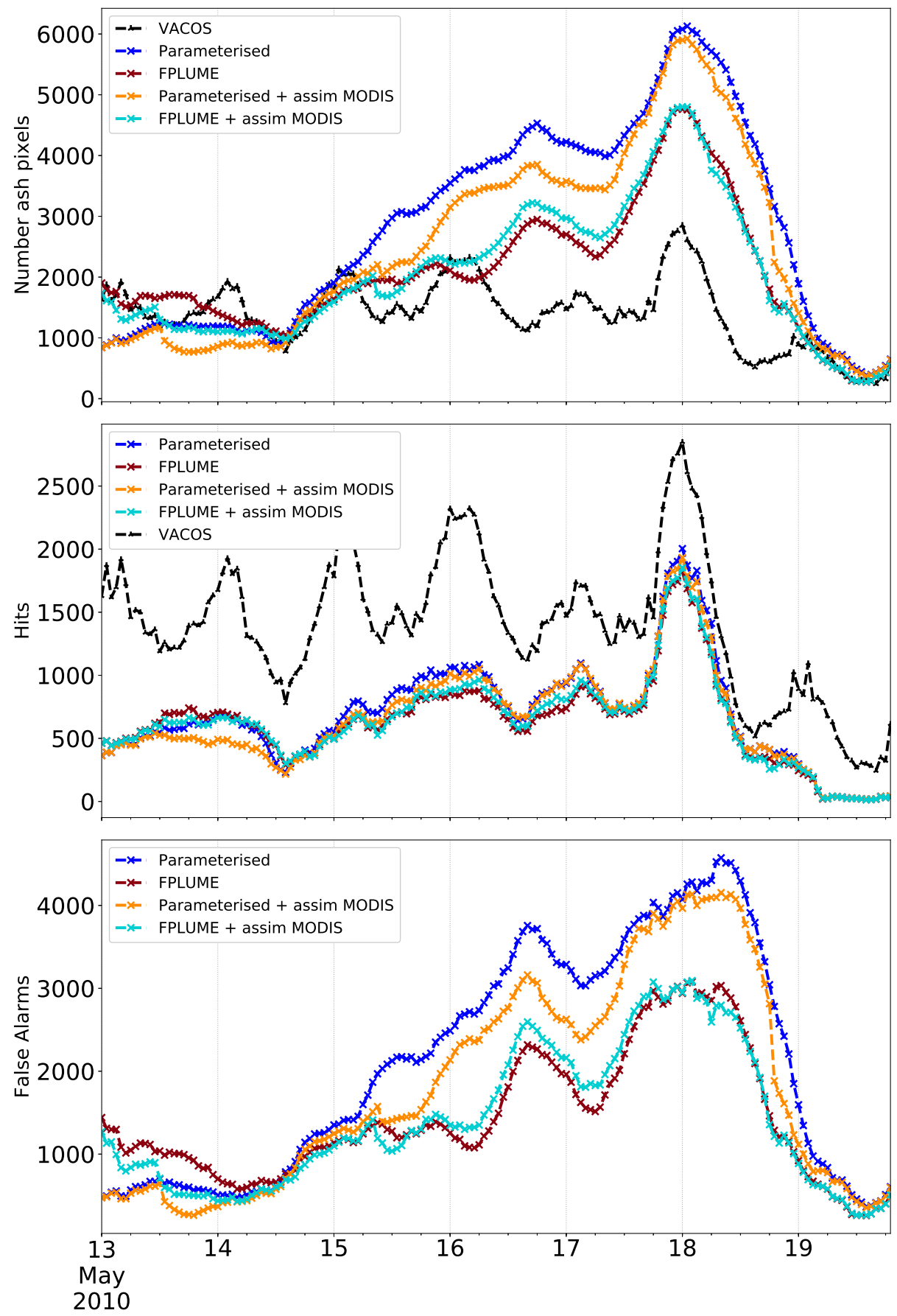

Figure 5. Comparison of the scores of ash contamination of the four MOCAGE runs (with parameterised/FPLUME source term, with or without assimilation of MODIS AOD observations), against VACOS ash estimates. From top to bottom: number of ash contaminated gridpoints in VACOS (black line) and MOCAGE simulations (colour lines) and source term height (grey shades), number of ash contaminated gridpoints in VACOS (black line) and also the number of hits for each simulation (gridpoints that are contaminated in both the simulation and in VACOS), and number of false alarms for each simulation (gridpoints that are contaminated in the simulation and not in the observation). 

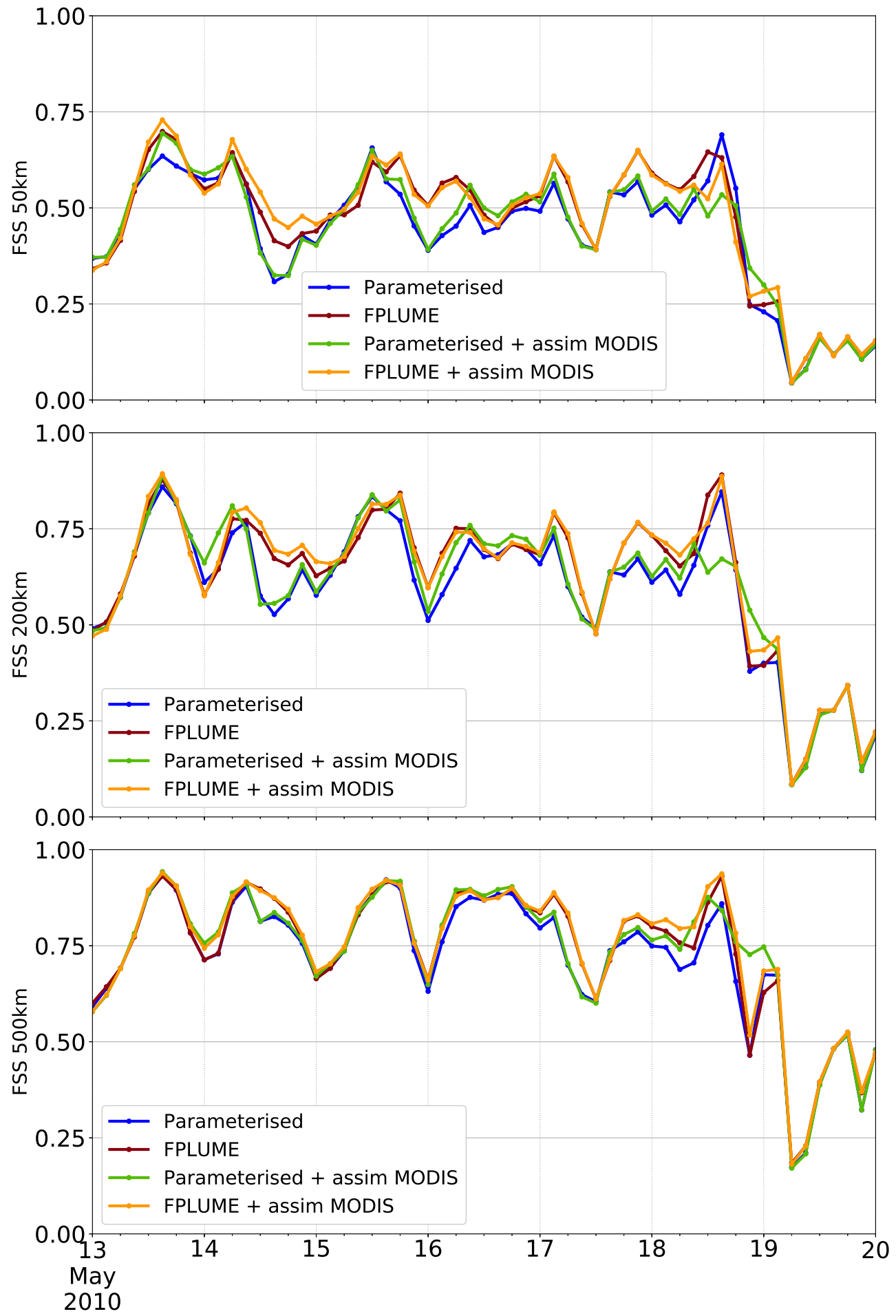

Figure 6. Comparison of the FSS of the four MOCAGE runs against VACOS estimates. The FSS values are shown for radii of 50km (first panel), 200km (second panel) and 500km (bottom panel). 

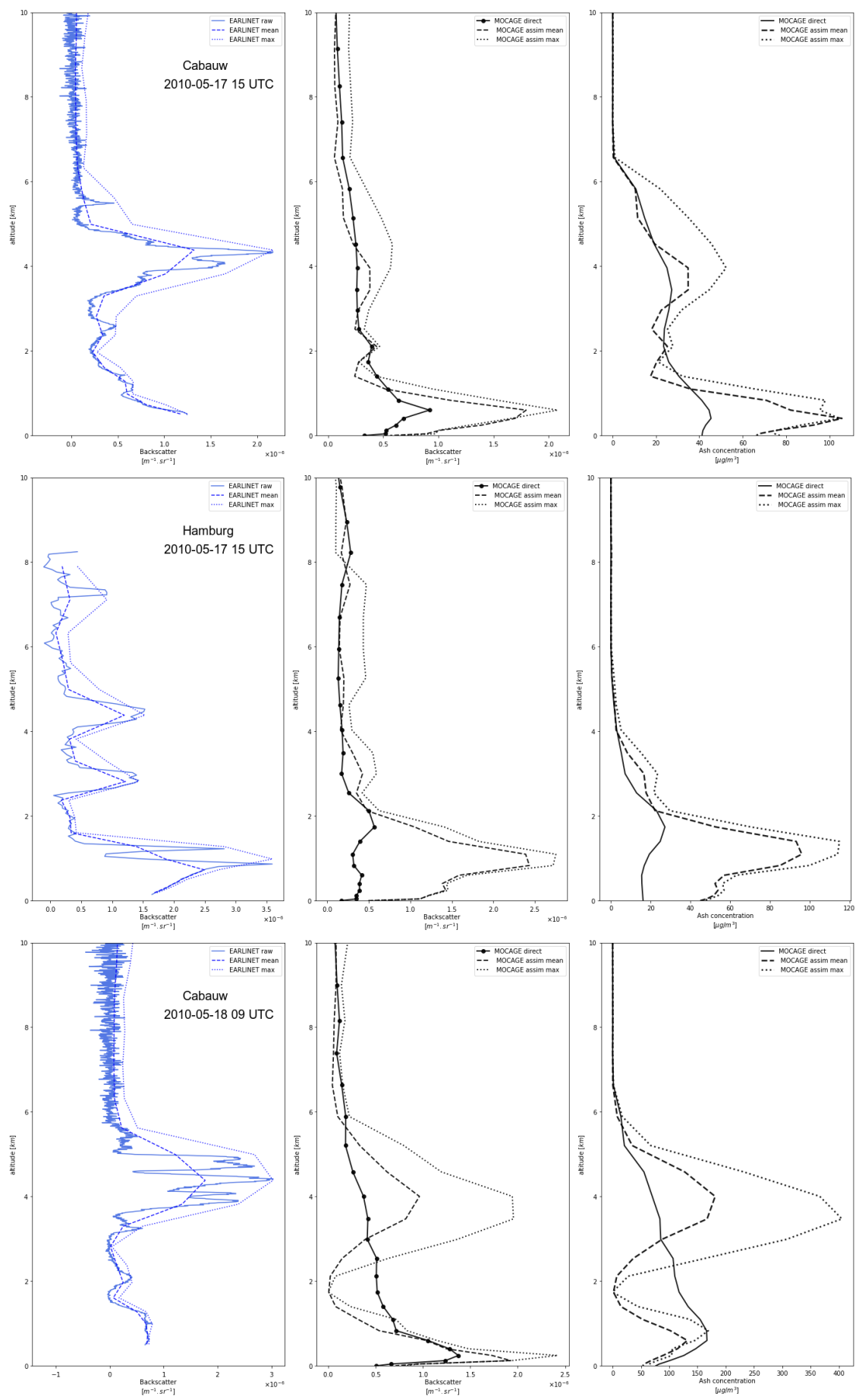

Figure 7. Vertical profiles of EARLINET backscatter coefficients (left column), of MOCAGE backscatter coefficients (middle column) and of MOCAGE ash concentrations (right column), at the Cabauw station on 17 May 2010 at 15 UTC (top row), at the Hamburg station on 17 May 2010 at 15 UTC (middle row) and at the Cabauw station on 18 May 2010 at 9 UTC (bottom row). From the original EARLINET profiles, mean- or max-values profiles are derived for assimilation in MOCAGE, at the vertical resolution of the model. The MOCAGE simulations are the direct run (without assimilation), and the two assimilation runs (using mean or max values) 

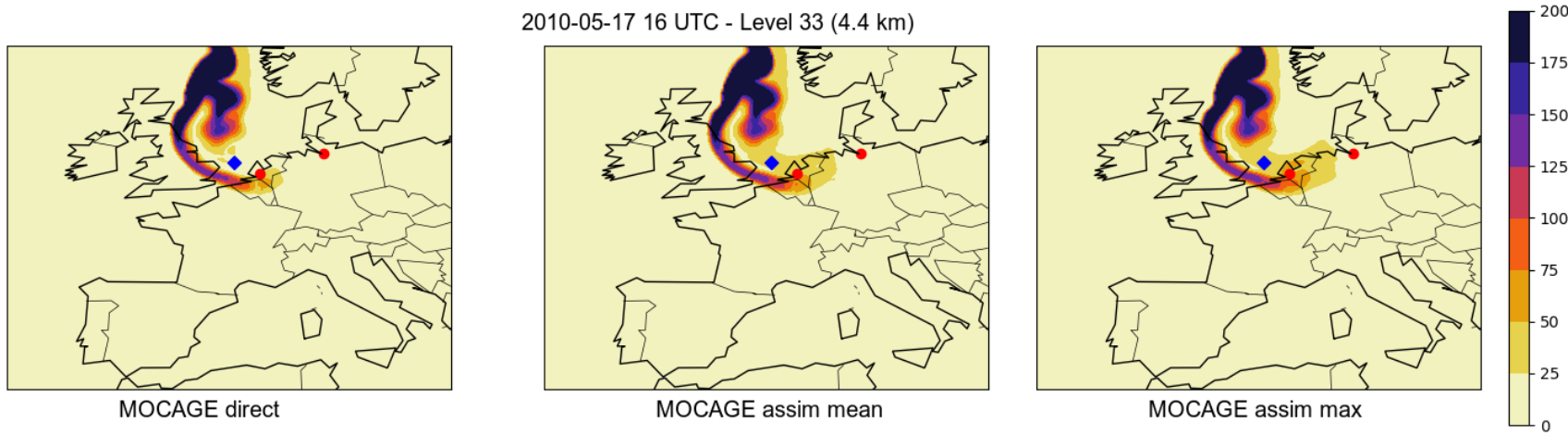

Figure 8. Comparison of volcanic ash concentration at level 33 (around $4.4 \mathrm{~km}$ ), on 17 May 2010 at 16 UTC, simulated by the MOCAGE direct run (without assimilation, left panel), by the MOCAGE run with assimilation of EARLINET mean profiles (middle panel), and by the MOCAGE run with assimilation of EARLINET max profiles (right panel). Ash concentration unit is $\mu \mathrm{g} . \mathrm{m}^{-3}$. The red dots indicate the Cabauw and Hamburg lidars, that are assimilated. The blue dots refer to the location of the flight legs where aerosol measurements are available.
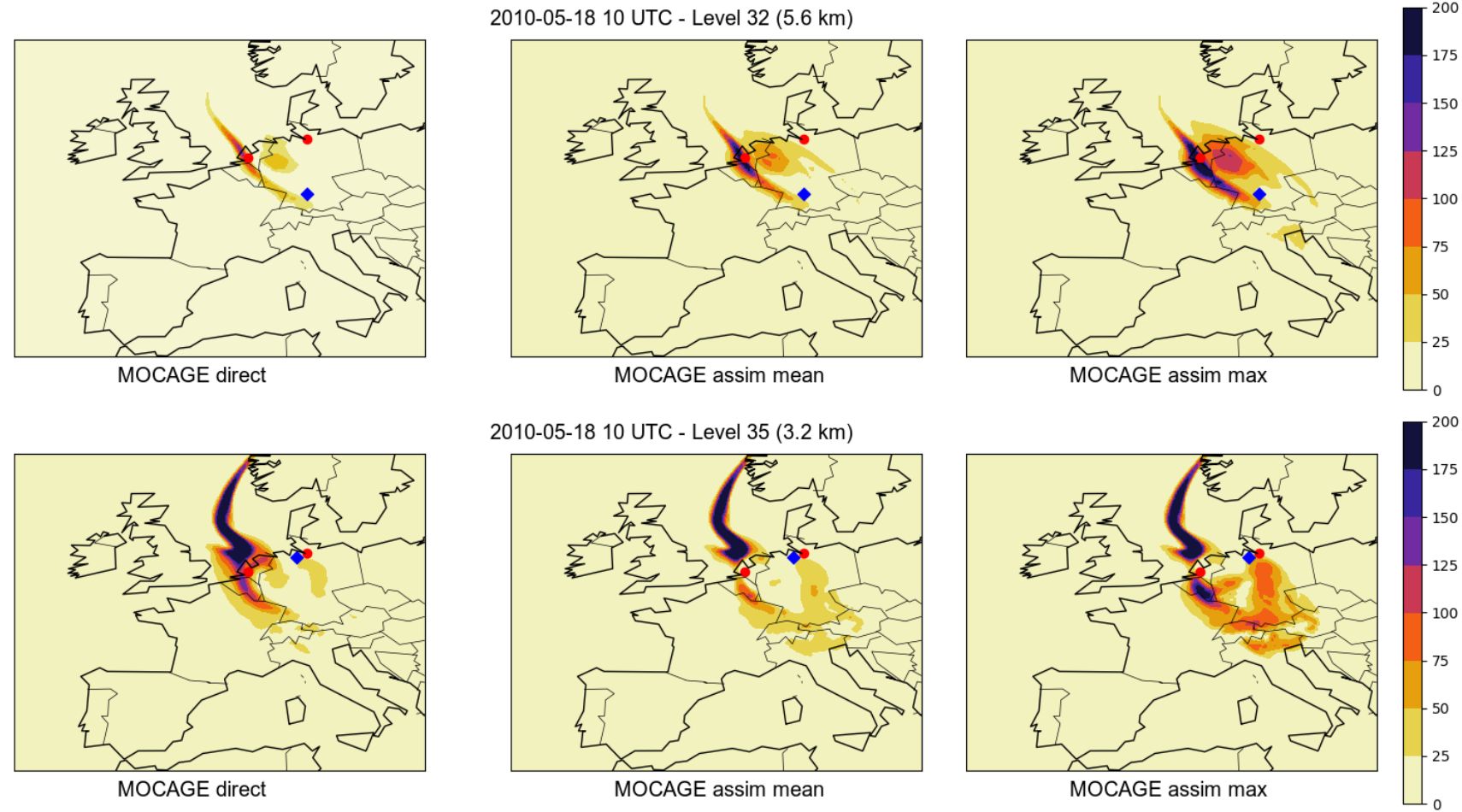

Figure 9. Same legend as Fig. 8, at level 32 (around $5.6 \mathrm{~km}$, top panels) and at level 35 (around $3.2 \mathrm{~km}$ ), on 18 May 2010 at 10 UTC. 